Journal of Sustainable Development of Transport and Logistics

journal home page: https://jsdtl.sciview.net

Gao, X., \& Li, T. (2018). Regional geographies of land transport networks in the Pearl River

Delta mega-region, China: A longitudinal analysis. Journal of Sustainable Development of

Transport and Logistics, 3(1), 37-52. doi:10.14254/jsdtl.2018.3-1.4.

\title{
Regional geographies of land transport networks in the Pearl River Delta mega-region, China: A longitudinal analysis
}

\author{
Xingchuan Gao *iD, Tao Li $* *$ \\ Shaanxi Normal University, \\ South Chang'an Road, Yanta District, Xi'an, China 710062 \\ * School of Geography and Tourism \\ ** Northwest Land and Resources Research Centre
}

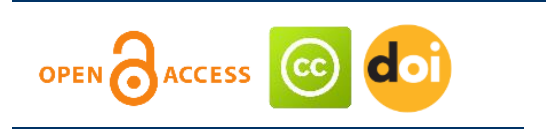

\section{Article history:}

Received: January 24, 2018

1st Revision: February 23,

2018

Accepted: March 19, 2018

\section{DOI:}

10.14254/jsdtl.2018.3-1.4

\begin{abstract}
This paper uses network-based efficiency measures to evaluate the efficiency implications of the evolution of the transport network in the Pearl River Delta (PRD) over the period 1988-2008. The network-based efficiency measures consider the relative ease of access between cities in terms of weighted relative travel cost. The results indicate that the spatial patterns of network efficiency are different from 'coreperiphery' pattern derived from classical accessibility indicators. This implies that there are low network efficiency cities and high network efficiency cities in core and peripheral regions at the same time. In the first stage (1988-1998), the efficiency contour shows a 'corridor' pattern along the GuangShen traffic corridor between Guangzhou and Shenzhen in the eastern side of the Pearl estuary; in the following decade (1998-2008), with large-scale infrastructural developments, the spatial pattern has changed from a north-south corridor to an east-west contiguous distribution pattern. By 2008, the mean network efficiency value indicates that the efficiency levels within the PRD as a whole are tending towards optimal levels. We conclude by suggesting ways to promote the urban economic development based on the relationship between the network efficiency and per capita GDP.
\end{abstract}

Keywords: transport network, network efficiency, spatiotemporal evolution, Pearl River Delta (PRD).

\section{Introduction}

It is well known that an efficient and reliable transport system forms the backbone for the development of any national or regional economy. As an important means of promoting the operational efficacy and service quality of transport systems, there have been many studies that measure and compare their efficiency in and between regions. However, the majority of this literature tends to focus on the performance of transport firms from a management perspective, so that the wider geographical

Corresponding author: Tao $\mathrm{Li}$

E-mail: 250077205@qq.com

This open access article is distributed under a Creative Commons Attribution (CC-BY) 4.0 license. 
aspects of the efficiency of transport networks have been frequently ignored or underemphasized (Lao \& Liu, 2009; Mesbah, Currie, Lennon, \& Northcott, 2012). This may be seen as rather surprising as a region's transport network efficiency geographies can strongly affect its socioeconomic development. It is, therefore, useful to examine transport network efficiency from a geographical perspective.

Against this backdrop, this paper attempts to improve our understanding of the impact of transport network developments on network efficiency. More specifically, this paper examines the efficiency implications of the evolution of the transport network in the Pearl River Delta (PRD), one of the most dynamic and fastest-growing regions of China. Since the adoption of economic reforms and the open-door policy in 1978, the PRD has experienced considerable changes in its transport infrastructures (Loo, 1999). Here we explore how the transport network efficiency and its geographies changed during the research period, and how these relate to the characteristics of urban and regional development. The main objective of this paper is network-based efficiency measures to evaluate the efficiency implications of the evolution of the transport network in the Pearl River Delta (PRD) over the period 1988-2008. The hypothesis of this paper is that transport network efficiency evaluation can better measure the impact of infrastructure improvement, and is different from the spatial pattern of the 'core-periphery' network efficiency, such as the classical accessibility index.

The remainder of this paper is structured in four main sections. The second section presents a brief review of the transport efficiency assessment literature. The third section briefly introduces the key characteristics of this paper's empirical setting, including the remarkable changes in the economy and the development of the transport network in the PRD. This is followed by discussions of the data and the methodology used in our network efficiency model, after which the fourth section presents an analysis of changes in network efficiency resulting from transport developments. Special attention is thereby given to the issue of geographical patterns of network efficiency. And finally, in the conclusions we present an overview of the most important findings and some avenues for further research.

\section{Transport efficiency analysis: a literature review}

Our research mainly relates two linked literatures. The first literature deals with transport efficiency from a management perspective, the second with transport efficiency from a geographical perspective. This section provides an overview of some of the most relevant points in both literatures.

\subsection{Transport efficiency assessment from a management perspective}

The term efficiency refers to the relationship between real or observed values of output(s) and input(s) and the optimal values of input(s) and output(s) used in a production process (Matthew G. Karlaftis \& Tsamboulas, 2012). As an important means of promoting the operational efficacy and service quality of transport systems, efficiency analysis has been one of the most widely investigated areas within transport research. For example, Fielding et al. $(1985 ; 1978)$ specified a set of indicators to measure the performance of public transit systems. These indicators were separated in three categories: efficiency, effectiveness and overall indicators. Based on this work, many authors have used the proposed indicators to analyse transit system efficiency and productivity (e.g. Gordon J. Fielding, 1992; Oum \& Yu, 1994; Talley \& Anderson, 1981). The advancement of data envelopment analysis (DEA) approach has generated a growing body of literature on applications in transport efficiency studies(Charnes, Cooper, \& Rhodes, 1978; Farrell, 1957). For example, Nolan (1996) investigated 25 mid-sized bus firms using US Department of Transportation section 15 data from 1989 to 1993 based on DEA model. Viton $(1997,1998)$ examined the technical efficiency of US multimode bus transit and discussed technological challenges facing the industry. Karlaftis (2004) analyzed the efficiency and effectiveness of 256 transit systems from 1990 to 1994. The results indicated positive relationships between efficiency and effectiveness. However, the optimal scale of operation was found to vary considerably amongst transit systems, depending on how outputs are specified in the DEA models. Tsamboulas (2006) evaluated the performance of 15 European transit systems operating under different regulatory regimes. In addition, some studies have explored the performance evaluation of airports and container ports (e.g. Feng \& Wang, 2000; Lao \& Liu, 2009; Liu, Liu, \& Cheng, 2006).

From this brief review of the existing literature, it can be inferred that despite there being a large body of research on transport efficiency, the majority of this literature focuses the performance of 
transport firms from a management perspective. In general, the efficiency of a transport firm, as measured by its inputs and outputs, is thereby compared with the efficiency of similar firms to determine the relative efficiency of the firm. As a consequence, relatively little attention has been paid to the wider geographical aspects of the efficiency of transport networks (Lao \& Liu, 2009; Mesbah et al., 2012), and how these relate to the characteristics of urban and regional development. Therefore, our research attempts to fill this gap by contributing to the literature evaluating efficiency of transport network at the regional scale.

\subsection{Transport efficiency from geographical perspective}

From an efficiency perspective, an efficient transport network facilitates and allows for the movement of goods, services, and people in a timely and reliable manner (Bell \& Feitelson, 1991). The presence of an efficient network is likely to improve accessibility, which refers to the ease with which activities may be reached from a given location by means of a particular transport system (Morris, Dumble, \& Wigan, 1979). Hansen (1959) defined accessibility as "the potential of opportunities for interaction", and proposed a method to measure it in metropolitan areas. Garrison (1960) thereupon introduced graph theory to calibrate topological accessibility. Since then, accessibility has been a widely used index for planners and transport researchers to study the performance of a transport network and its relations with urban and regional development. Well-known examples include 'economic potential indicators' (e.g. Geertman \& Van Eck, 1995; Harris, 1954; Keeble, Offord, \& Walker, 1988; Linneker \& Spence, 1992), 'potential transport cost indicators' (e.g. Botham, 1980; Harris, 1954), and 'location indicators' (e.g. Gutierrez, Gonzalez, \& Gomez, 1996; Javier Gutiérrez \& Urbano, 1996).

In the PRD, like in other regions, there have been many urban and regional studies that measure the impact of transport network evolution on accessibility. At the urban scale, Cao and Yan (2003) examined road and railway network evolutions and the changing accessibility in Dongguan, Guangdong Province, over the period 1980-2000. At the regional scale, Loo (1999) examined the impact of the 'Open Door Policy' on the transport geographies of the PRD between 1980-1995, and discovered that major transport infrastructural improvements have been relatively concentrated along the high traffic corridors, and that different types of transport infrastructural projects are more closely associated with different dimensions of development. Li and Cao (2012) found that the spatial pattern of accessibility in the PRD did show a 'core-periphery' model, where the most accessible areas in the PRD stretch discontinuously along the eastern side of the Pearl River's estuary. The less accessible areas are the most peripheral ones, namely the eastern and western regions in the PRD. Similarly, Hou and Li (2011) analysed the accessibility implications of the development of expressways and inter-city railways in the Greater Pearl River Delta (GPRD) over the period 1990-2020 and found average travel time was firstly reduced by expressway development; and suggested that it would be reduced further by the introduction of the inter-city rail system in 2011. The spatial pattern of economic potential in the GPRD has changed from a single-pole (Hongkong) and steep-gradient one to a double-pole (Hongkong and Guangzhou) and more spatially diffused one.

In general, the accessibility indicators used in the above mentioned papers depends on two concepts that act in an opposite direction: costs and attraction of economic activity to a destination (MartÍn, Gutierrez, \& Román, 2004). Transport costs represent a proxy of the difficulties or resistance to the movement of freight and persons between two nodes in a given network. They are usually expressed in different units, such as distance, travel time or generalized cost of transport. The attraction of a destination depends on its population, employment or Gross Domestic Product (GDP). The value of accessibility is determined by the transport cost between two nodes and the attraction of destination. However, these methods are concerned more with the absolute distance (time) of spatial separation amongst places when calculating accessibility, and thus tend to ignore or underemphasize the efficiency aspects inherent to this problem. As a consequence, results offered by these indicators tend to display a typical concentric 'core-periphery' pattern (Vickerman, 1995), where peripheral regions invariably figure as being of low accessibility, even though they may be well-connected in transport infrastructures. Therefore, the aforementioned accessibility analyses are of relatively little help when looking for the infrastructure development effects on accessibility from an efficiency perspective.

To overcome this deficiency, some studies have measured transport network efficiency through the comparison between actual link-distance between any two points and the optimal distance between 
them. For example, Gutierrez (1998) proposed a network efficiency indicator and applied it in the context of the 'Spanish Infrastructure Master Plan'. In order to neutralize the effect of geographical location of places in the distance calculations, the notion of absolute distance is thereby substituted by another measure expressing the ease of access in terms of network efficiency. In addition, based on complex network theory, Latora $(2001,2002)$ studied the Boston subway network through the use of a network efficiency measure defined by the mean value of inverse distances between network nodes.

\section{Economic and transport development in the Pearl River Delta}

\subsection{Economic expansion}

In this paper, the Pearl River Delta (PRD) refers to the Pearl River Delta Economic Region (PRDEG), excluding Hong Kong and Macau. The PRD is located at the centre of Guangdong province bordering Hong Kong to the eastern side of the Pearl estuary, and Macau to the western side of the Pearl estuary (Fig 1). It encompasses nine prefecture-level cities and eleven county-level cities with a total population of 56 million in 2011 (N. B. o. S. o. China, 2012) and covering a total area 41,393 km².

The PRD has experienced rapid economic development over the last three decades, following the adoption of economic reform and the open-door policy of China in 1978. Geographical proximity to Hong Kong and extensive social relations with overseas Chinese entrepreneurs led to the PRD being chosen as the first area to practice flexible economic policies by Chinese central government (Lin, 2001). Since 1979, four types of 'openness' have been established across the entire regions: the Special Economic Zones (SEZs) of Shenzhen and Zhuhai, the Open Coastal Cities (OCCs) of Guangzhou, the Economic and Technological Development Zones (ETDZs) in Guangzhou, and the Open Coastal Economic Area (OCEA). The opening up of the PRD coincides with the global shift of manufacturing activities from advanced to newly industrializing economies since the 1980s (Dicken, 2011). The PRD's gross domestic production (GDP) has increased very rapidly from 11 billion Yuan in 1979 to 4370 billion Yuan in 2011 (N. B. o. S. o. China, 2012), and the level of urbanization has increased from $13.2 \%$ in 1979 to $83.0 \%$ in 2011 (N. B. o. S. o. China, 2012). Today, the PRD ranks as one of the fastest growing and globalizing city-regions in the world (X.Zhang \& R.C.Kloosterman, 2012), and as one of the five most urbanized areas in China along with the Yangtze River Delta, the Beijing-Tianjin-Tangshan area, the Shenyang-Dalian region and the Eastern Shandong Peninsula area in China (Zhang, 1995).

Figure 1: The study area - Pearl River Delta (PRD)

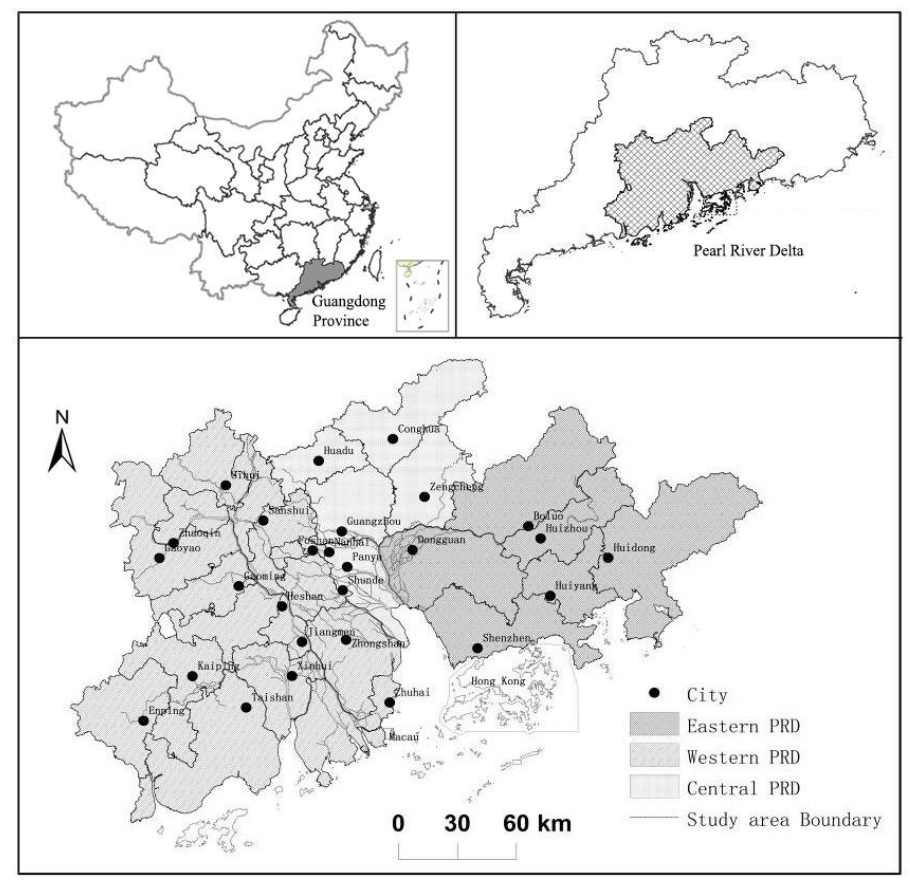




\subsection{Road networks}

In parallel with these economic developments, there have been remarkable developments in the PRD's transport networks. On the eve of the Open Door Policy, transport networks were both sparse and underdeveloped (Loo, 1999). Under the economic reforms, the quality of the transport infrastructure has been improved dramatically in order to satisfy increasing transport demands induced by rapid economic development. Figure 2 a represents the highway network in 1988, which comprises of a total of $21,329 \mathrm{~km}$ divided into national roads, provincial roads and county roads. The density of the network stood at $51.53 \mathrm{~km}$ per $100 \mathrm{~km}^{2}$ (Table 1). During the first stage (1988-1998), the geographies of these highway networks remained almost unchanged, but there was a significant upgrading of the existing transport infrastructures. In this period, the total length of highways increased slightly from 21,329 to $29,888 \mathrm{~km}(+40.13 \%)$. By 1998 , the density of network stood at $72.21 \mathrm{~km}$ per $100 \mathrm{~km}^{2}$ (Figure 2b). During the second period (1998-2008), the further upgrading the transport infrastructures started going hand in hand with large-scale expansion. The total length of highways increased rapidly from 29,888 in 1998 to 53,536 km $2008(+79.12 \%)$. By 2008, the density of the network stood at $129.34 \mathrm{~km}$ per $100 \mathrm{~km}^{2}$, whereby the geographical structure of the highway network has changed markedly: while the network initially resembled a star-shaped network with Guangzhou at the centre of the network, and all major cities in the PRD connected by expressways (Figure 2c). According to the Planning of Integrated Infrastructure Development in the Pearl River Delta (2009-2020) drafted by the Guangdong Provincial Government (2010), the total length of highways and the density of the network will reach to $55856 \mathrm{~km}$ and $134.94 \mathrm{~km}$ per $100 \mathrm{~km}^{2}$ in 2020 and all cities in the PRD will be connected by expressways.

\subsection{Rail networks}

From 1949 to 1980, the single-track North-South Beijing to Kowloon (Hongkong) Railway was the only railway line in the PRD (Loo, 1999). Although many major railway construction and improvement projects have taken place under the Open Door Policy, Guangdong lags far behind other regions in China in terms of rail network developments. By the end of 2008, the total length of railways in operation in the PRD was $514 \mathrm{~km}$, which is - given the region's overall economic prominence - a meagre $0.65 \%$ of the national total. Figures $2 \mathrm{a}-2 \mathrm{c}$ maps the evolution of the rail network over the research period. It can be observed that the railway network has remained almost unchanged, and can still be described as a tree structure involving no circuit. There are only four railway lines running across the PRD: the GuangzhouShaoguan sections of the Beijing-Guangzhou Railway, the Guangzhou-Shenzhen Railway (further extended to Kowloon in Hong Kong), the Guangzhou-Foshan Railway, and the Guangzhou-MeizhouShantou Railway. By 2020, it foresees the construction of $1445 \mathrm{~km}$ of intercity railways, and the railway network in the PRD will feature several circuits and strategic nodes, in particular Guangzhou in Central PRD, Shenzhen on the east and Zhuhai on the west.

Figure 2a: The evolution of land-based transport network in the PRD, 1988

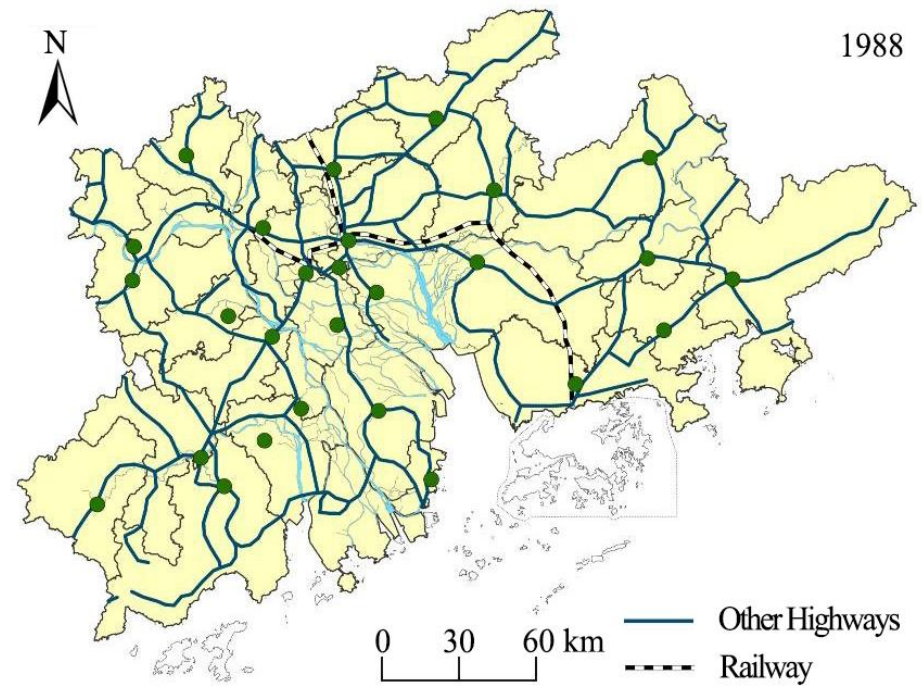


Figure 2b: The evolution of land-based transport network in the PRD, 1998

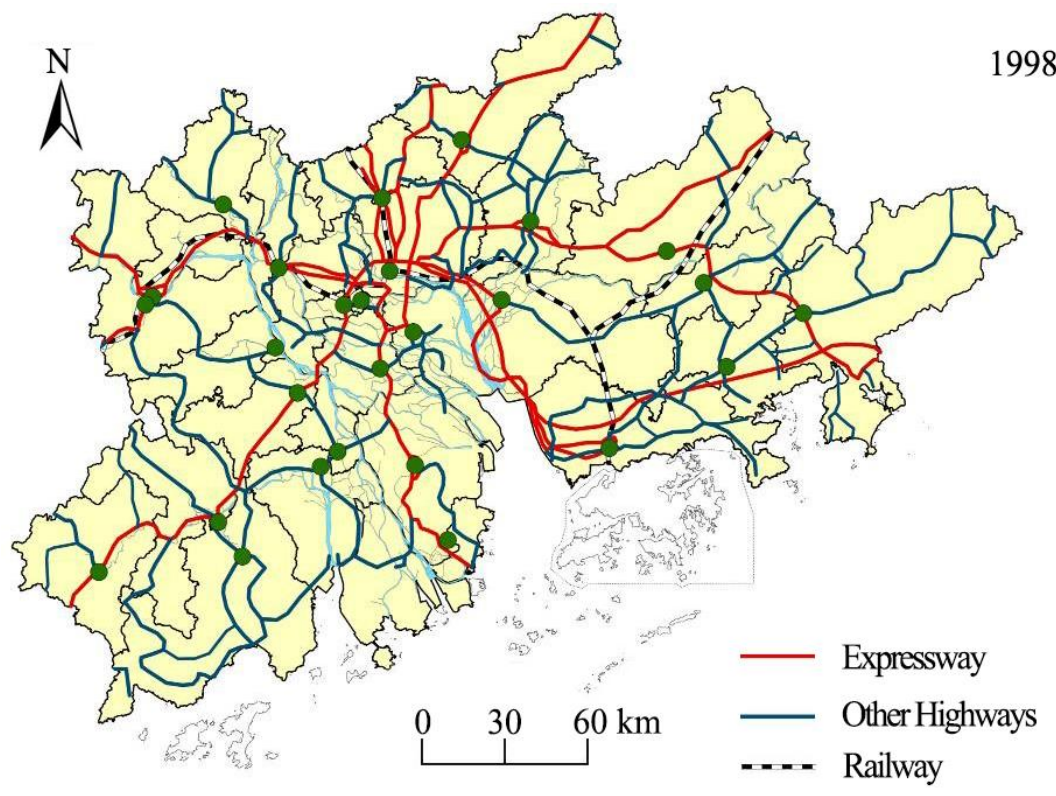

Figure 2c: The evolution of land-based transport network in the PRD, 2008

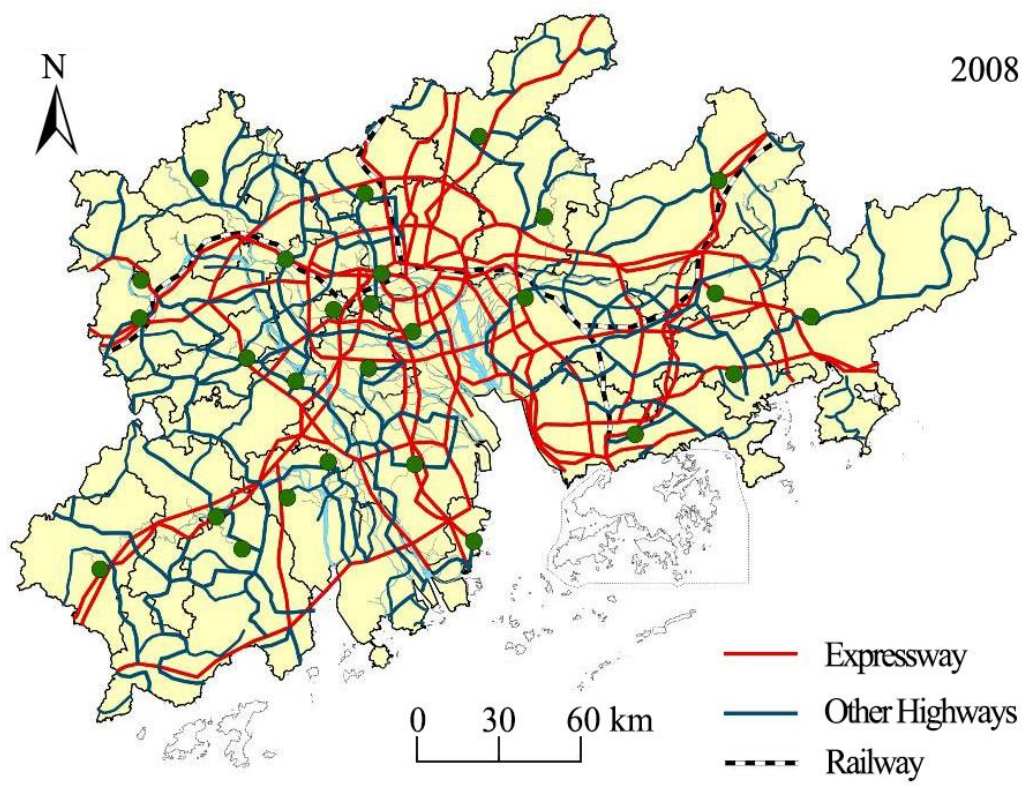

In order to demonstrate the geographical unevenness of highway network development over the research period, table 1 makes a comparison of network characteristics within the different sub-regions of the PRD. We assess the spatial unevenness of highway network formation by measuring changes to the coefficients of variation in network length and density respectively. The coefficient of variation (COV), calculated by dividing a distribution's standard deviation by its mean, is a standard measure of inequality. Smaller values imply relatively less dispersal. The results indicate that the distribution of network length and density grew more equal over 1988-2008 period. The COV of network length declined from 0.81 to 0.66 and the COV of network density declined from 0.30 to 0.26 . In substantive terms, this means that the massive expansion of the highway network has considerably decreased the spatial unevenness of the highway distribution. This is corresponding with the aforementioned characteristics of transport network development. 
Table 1: Comparisons of network length and density in the PRD, 1988-2008

\begin{tabular}{ccccccccccc}
\multirow{2}{*}{ Year } & \multicolumn{2}{c}{ Eastern PRD } & \multicolumn{2}{c}{ Central PRD } & \multicolumn{2}{c}{ Western PRD } & \multicolumn{3}{c}{ PRD } \\
\cline { 2 - 36 } & Length & Density & Length & Density & Length & Density & Length & Density & COV $_{l}$ & COV $_{n}$ \\
\hline 1988 & 6124 & 39.32 & 3547 & 47.71 & 11658 & 36.74 & 21329 & 51.53 & 0.81 & 0.30 \\
1998 & 10094 & 64.80 & 4367 & 58.74 & 15427 & 48.61 & 29888 & 72.21 & 0.68 & 0.33 \\
2008 & 16459 & 105.67 & 8781 & 118.12 & 28296 & 89.17 & 53536 & 129.34 & 0.66 & 0.26 \\
\hline
\end{tabular}

Notes: Data was compiled from the statistical yearbooks of individual municipalities, 1988, 1998, and 2008; $\mathrm{COV}_{l}$ stands for coefficient of variation of highway network length; $\mathrm{COV}_{n}$ stands for coefficient of variation of highway network density.

\section{Data and Methodology}

\subsection{Transportation network, socio-economic activity data}

Based on the availability and statistical consistency of the data, the following years were selected for assess the transport network: 1988, 1998 and 2008. The county level administrative unit (including county level city, county and district) and the urban district are used due to its nature as the basic spatial unit for studying socio-economic development in the PRD. Although there have been numerous changes in the administrative system after the Open Door Policy, boundaries at the county level have remained relatively stable. The spatial administrative boundaries data come from the National Fundamental Geographic Information Database provided by National Geomatics Centres of China (2010) and the spatial references for the county in the network efficiency calculations were the actual location of the main centres (Fig. 1). The names of these cities, together with their administrative status and sizes, are listed in appendix B.

With respect to transport infrastructure network data, network efficiency at the county levels is analysed using GIS-based models of land-based transport network, composed by the highway and railway networks connected through the railway stations. The highway and railway network (including highways, expressways and railways) come from the map of transportation atlas published by China Communication Press $(1988,1998,2008)$. We first conducted projection transformation of graphic data based on ArcGIS Desktop 10.1 software platform, after which the transport network data were digitized manually and stored into Geodatabase.

Economic opportunity is typically represented by population and gross domestic product (GDP). In this study, population and GDP data are extracted from the statistical yearbooks of individual municipalities.

\subsection{Methodology}

\subsubsection{Network efficiency}

The term network efficiency refers to the comparison between real and optimal levels of demand for traffic. Drawing on Gutierrez (1998), the network efficiency indicator is calculated as follows:

$$
E_{i}=\sum_{j=1}^{n} \frac{N_{i j}}{S_{i j}} \times M_{j} / \sum_{j=1}^{n} M_{j}
$$

where:

$N_{i j}$ is the actual network impedance through the network between node $i$ and $j$ (in time); $S_{i j}$ is the virtual optimal network impedance between node $i$ and node $j$ (in time); and $M_{j}$ is the 'mass' of the destination city.

In this paper, actual network impedance between any pair of nodes is obtained by calculating the fastest route between both. The Euclidean distance between any pair is the optimal network impedance, and is obtained through a hypothetical straight line of expressway link strength. The population $\left(P O P_{j}\right)$ and GDP $\left(G D P_{j}\right)$ of each destination are selected as the weighting factors, and are calculated as $M_{j}=$ $\sqrt{G D P_{j} \times P O P_{j}}$. 
The network efficiency was calculated between 27 pairs of cities in the PRD over the research period. In order to demonstrate the actual infrastructure improvements on the patterns of network efficiency (for example: countering endogeneity effects), the GDP and population measure were considered to be fixed. This implies that each city in the network has the same GDP value and population in 1988, 1998 and 2008, respectively. In this paper, 2005 population and GDP data are used for the computation for 1988, 1998 and 2008.

This approach can in practice be conceived as a weighted average time accessibility indicator. As Gutierrez (1998) points out, it allows to single out the pure infrastructure improvements on the geographical patterns of network efficiency. The custom notion of distance is substituted by the ratio $N_{i j}$ $/ S_{i j}$, which expresses how much the network impedance surpasses the Euclidean impedance, so that the results obtained from the formula neutralize the effects of geographical location. In other words, when the infrastructure connecting the nodes to the various economic activity centres is very efficient, nodes will receive a network efficiency value tending to towards 1, while a value equal to 2 means that the network impedance is twice the Euclidean impedance.

\subsubsection{Network impedance indicator}

The network efficiency model detailed in the previous section does, however, not consider the real transport network traffic capacity: express highways or major train lines lead to faster travel times. In order to circumvent this problem, we add the infrastructure quality as a weight for computing the network impedance metric, using the equation defined by Gutierrez (1998):

$$
N_{i j}=T_{i j}\left(1+c_{i j}^{i}\right)
$$

where $c_{i j}^{i}$ is the coefficient of infrastructure quality, which takes the following values: -0.2 for expressways and railways, 0.0 for national roads, 0.2 for provincial roads and 0.4 for other roads.

For each arc on the highway network, the length and estimated speed was recorded, after which travel time can be calculated. According to The Technical Standard of Highway Engineering of the People's Republic of China (JTGB01-2003) and the actual situation at different periods, the estimated speeds take the following values: $50 \mathrm{~km} / \mathrm{h}$ for National roads, $40 \mathrm{~km} / \mathrm{h}$ for Provincial roads, $30 \mathrm{~km} / \mathrm{h}$ for other roads in 1988. In 1998 this was $90 \mathrm{~km} / \mathrm{h}$ for Expressways, $70 \mathrm{~km} / \mathrm{h}$ for National roads, $60 \mathrm{~km} / \mathrm{h}$ for Provincial roads, and $40 \mathrm{~km} / \mathrm{h}$ for other roads. By 2008, values were taken to be $120 \mathrm{~km} / \mathrm{h}$ for Expressways, 80 $\mathrm{km} / \mathrm{h}$ for National roads, $70 \mathrm{~km} / \mathrm{h}$ for Provincial roads, and $50 \mathrm{~km} / \mathrm{h}$ for other roads. Distance and travel time for the existing railways were obtained from the The Time table of National Railway Operation published by China Railway Publishing House $(1988,1998,2008)$. The shortest travel time between each node for 1988, 1998 and 2008 can be acquired by use of ArcGIS 10.1 network analyst module, and then we can calculate the weighted relative travel cost (network efficiency) of the transport network based on (2).

\section{Network efficiency analysis of the transport network in the PRD}

\subsection{Network efficiency results}

Network efficiency analysis was applied to the land-based transport network, consisting of highways and railways connected by railway stations. Based on Eq. (1) and (2), the nodal network efficiency $E_{i}$ is computed in this study. Table 2 presents an overview of nodal network efficiency $E_{i}$, and the absolute and relative change of the network efficiency values for selected cities over time. Figs. 4(a) through (c) map the contours of nodal network efficiency of the transport network in 1988, 1998, and 2008 , respectively. 
Table 2: The network efficiency in the PRD, 1988-2008

\begin{tabular}{|c|c|c|c|c|c|c|c|}
\hline \multirow{3}{*}{ City } & \multicolumn{3}{|c|}{ Network efficiency value } & \multicolumn{4}{|c|}{ Changes in network efficiency } \\
\hline & \multirow{2}{*}{1988} & \multirow{2}{*}{1998} & \multirow{2}{*}{2008} & \multicolumn{2}{|c|}{$88-98$} & \multicolumn{2}{|c|}{ 98-08 } \\
\hline & & & & Absolute & Relative & Absolute & Relative \\
\hline Guangzhou(GZ) & 3.23 & 1.76 & 1.04 & 1.47 & 45.41 & 0.72 & 41.08 \\
\hline Sihui(SH) & 3.24 & 2.12 & 1.97 & 1.12 & 34.66 & 0.14 & 6.70 \\
\hline Sanshui(SS) & 3.33 & 1.98 & 1.35 & 1.35 & 40.44 & 0.64 & 32.13 \\
\hline Zhaoqin(ZQ) & 3.49 & 2.33 & 1.38 & 1.17 & 33.40 & 0.95 & 40.67 \\
\hline Shenzhen(SZ) & 3.57 & 1.77 & 1.07 & 1.80 & 50.35 & 0.70 & 39.57 \\
\hline Foshan(FS) & 3.59 & 2.10 & 1.54 & 1.49 & 41.53 & 0.57 & 26.88 \\
\hline Gaoyao(GY) & 3.67 & 2.35 & 1.45 & 1.32 & 35.86 & 0.90 & 38.43 \\
\hline Dongguan(DG) & 3.71 & 2.01 & 1.34 & 1.70 & 45.84 & 0.68 & 33.59 \\
\hline Huizhou(HZ) & 3.72 & 2.76 & 1.33 & 0.96 & 25.83 & 1.43 & 51.97 \\
\hline Huadu(HU) & 3.75 & 1.94 & 1.39 & 1.81 & 48.30 & 0.55 & 28.28 \\
\hline Enping(EP) & 3.97 & 2.58 & 1.18 & 1.39 & 34.90 & 1.40 & 54.34 \\
\hline Huidong(HD) & 4.01 & 2.31 & 1.38 & 1.70 & 42.34 & 0.93 & 40.36 \\
\hline Conghua(CH) & 4.10 & 2.31 & 1.14 & 1.78 & 43.55 & 1.17 & 50.65 \\
\hline Nanhai(NH) & 4.15 & 2.20 & 1.35 & 1.95 & 46.99 & 0.85 & 38.49 \\
\hline Boluo(BL) & 4.23 & 3.09 & 1.29 & 1.14 & 26.90 & 1.80 & 58.31 \\
\hline Kaiping(KL) & 4.35 & 2.57 & 1.44 & 1.79 & 41.00 & 1.13 & 43.91 \\
\hline Shunde(SD) & 4.55 & 2.57 & 1.39 & 1.98 & 43.53 & 1.18 & 45.89 \\
\hline Heshan(HS) & 4.58 & 2.55 & 1.38 & 2.02 & 44.19 & 1.17 & 45.84 \\
\hline Gaoming(GM) & 4.65 & 3.53 & 1.41 & 1.13 & 24.22 & 2.12 & 60.02 \\
\hline Taishan(TS) & 4.87 & 2.90 & 1.57 & 1.98 & 40.59 & 1.33 & 45.79 \\
\hline Zengcheng(ZC) & 4.98 & 2.85 & 1.35 & 2.13 & 42.86 & 1.50 & 52.64 \\
\hline Huiyang(HY) & 5.25 & 2.40 & 1.54 & 2.85 & 54.25 & 0.86 & 35.68 \\
\hline Panyu(PY) & 5.43 & 3.90 & 1.44 & 1.53 & 28.19 & 2.46 & 63.09 \\
\hline Zhongshan(ZS) & 5.54 & 3.29 & 1.31 & 2.25 & 40.66 & 1.98 & 60.27 \\
\hline Xinhui(XH) & 5.68 & 3.09 & 1.04 & 2.59 & 45.61 & 2.05 & 66.27 \\
\hline Jiangmen(JM) & 6.02 & 3.11 & 1.17 & 2.91 & 48.39 & 1.94 & 62.42 \\
\hline Zhuhai(ZH) & 7.65 & 4.07 & 2.74 & 3.58 & 46.77 & 1.34 & 32.78 \\
\hline Mean & 4.42 & 2.61 & 1.41 & 1.81 & 40.95 & 1.20 & 45.97 \\
\hline S.D. & 1.02 & 0.61 & 0.33 & & & & \\
\hline $\mathrm{COV}$ & 0.23 & 0.23 & 0.23 & & & & \\
\hline
\end{tabular}

Note: S.D. refers to standard deviation of network efficiency; COV stands for coefficient of variation of network efficiency; The lower the network efficiency value, the more accessible the place in network efficiency terms.

Overall, the spatial pattern of network efficiency is different from the 'core-periphery' pattern derived from classical accessibility indexes (see the Appendix A). In 1988 and 1998, the high level of network efficiency attained along the GuangShen traffic corridor (including the expressway and railway) between Guangzhou and Shenzhen in the eastern side of the Pearl estuary, especially at the intersection of highways, such as Guangzhou, Dongguan, and Shenzhen. The effects of this corridor even reach certain cities on the northwestern and southeastern regions in the PRD, such as Sihui and Huiyang. In addition, there are also good efficiency conditions in certain 'islands', corresponding to important nodes on the network, such as Enping and Huizhou. The less accessible areas are located outside these corridors that were served by sparse and low-grade infrastructures, such as Jiangmen, Xinhui and Taishan in the Western PRD. In the following decade, there were generalized improvements in terms of network efficiency, due to the large-scale transport infrastructural construction and upgrading on many of the existing lines. Further transport infrastructure development improved network efficiency above all in the Western PRD and Eastern PRD, and the spatial pattern has changed from an original northsouth corridor to east-west contiguous distribution pattern. 
The network efficiency value in the PRD as a whole shows significant improvement. In the first ten years (1988-1998), the average network efficiency value of cities improved as can be seen from the decrease from 4.42 to 2.61 , a drop of $41 \%$. Over the following decade (1998-2008), further highway extensions reduced this average value to 1.41 , a further drop of $46 \%$. In relative terms, the marginal effect increased over time, which was in line with previous analysis on the evolution characteristics of transport infrastructure in third section. As mentioned above, during the first research period (19881998), the total length of highways increased slightly from 21,33 to $29,889 \mathrm{~km}(+40.13 \%)$. During the second period (1998-2008), the total length of highways increased rapidly from 29,888 in 1998 to $53,536 \mathrm{~km} 2008(+79.12 \%)$.

As can be seen in the results given in Table 2, Sihui stands out to be the city that experiences the largest improvement in network efficiency implication, both in absolute (4.64) or relative (81.66\%) terms. Not surprisingly, Guangzhou, the provincial capital of Guangdong, constantly ranks highest in terms of the network efficiency value, due to its central location in the PRD's overall transport network. In contrast, Zhuhai, located in the southwest side of the Pearl estuary area, constantly ranks the lowest in terms of the network efficiency value. This is to be expected given that the Pearl Estuary, acting as a major barrier to transport connection between the western wing and eastern wing. In fact, this natural barrier plus the low level transport infrastructures development has hindered the development of the Western PRD. This situation will possibly change dramatically in the near future. The Guangdong Government presented a Planning of Integrated Infrastructure Development in the PRD. The Planning of the Intercity Railway in the PRD, of which the horizon is the year 2020, consists of some $1445 \mathrm{~km}$ of new lines, including a Guangzhou-Zhuhai intercity railway, West Guangdong Coastal railway. Also, the construction of the HK-ZH-MC Bridge, which connects Hong Kong, Zhuhai and Macau, started construction began on 15 December 2009 and is scheduled to be open for traffic in 2015. These transport projects will significantly augment the interconnection between the Eastern PRD and Western PRD.

Figure 4a: The network efficiency (NE) of land-based transport network in the PRD, 1988

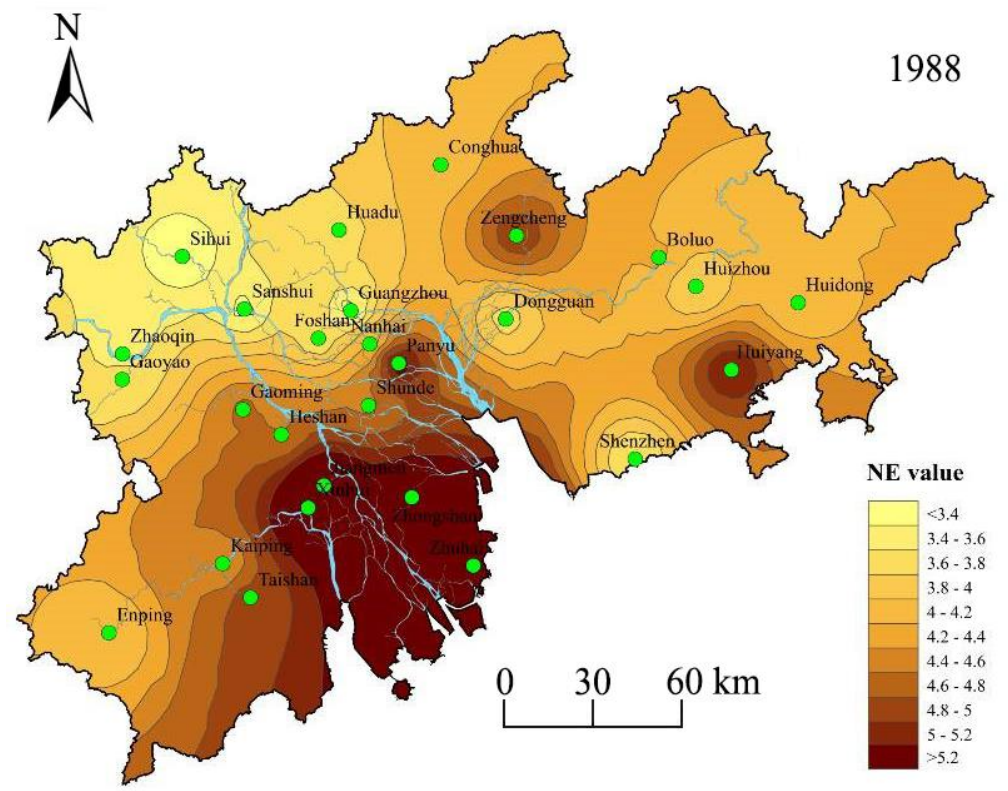


Figure 4b: The network efficiency (NE) of land-based transport network in the PRD, 1998

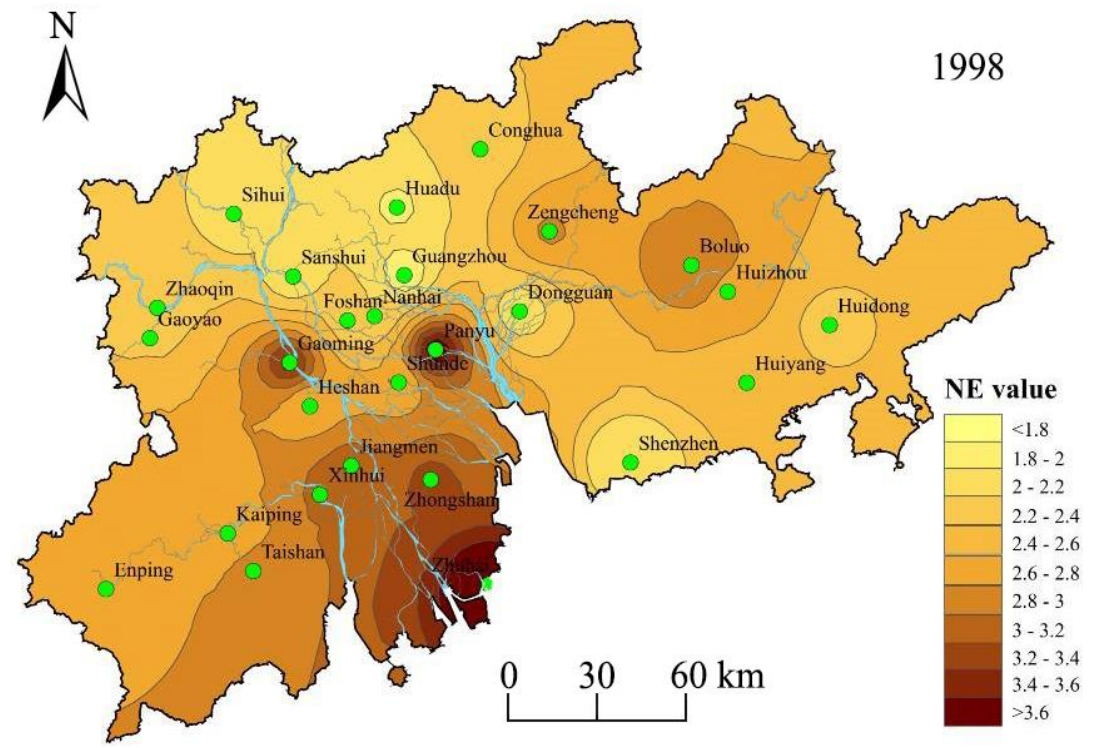

Figure 4c: The network efficiency (NE) of land-based transport network in the PRD, 2008

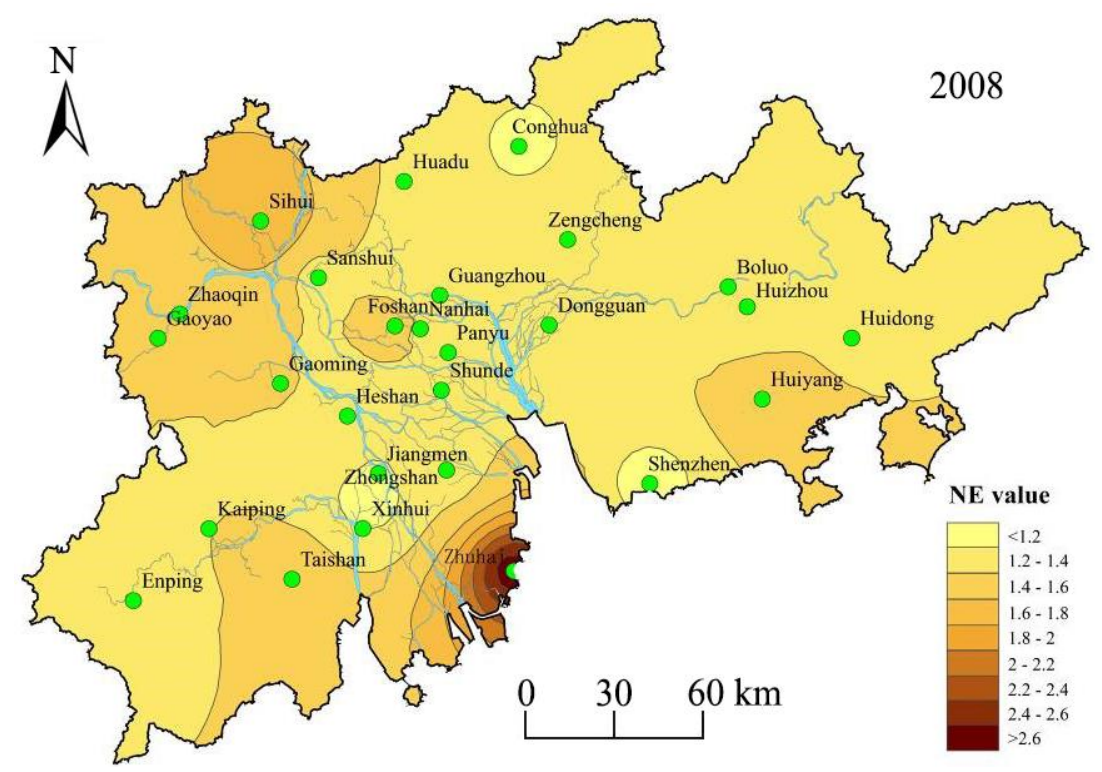

The above-mentioned improvements can easily be detected with the analysis of the Figs. 5, which map the relative change in network efficiency value for the periods 1988-1998 and 1998-2008, respectively. It can be observed that, the area with higher efficiency shifted gradually from the central regions to the eastern and western regions. During 1988 and 1998, higher efficiency benefits mainly concentrate in GuangShen (Guangzhou-Shenzhen) traffic corridor above mentioned and spread to eastern and western side of Pearl Estuary, due to the infrastructure development mainly distributed in this area, such as Huadu, Huiyang, Jiangmen, Xinhui and Zhuhai. But the improvements recorded for rest western and eastern cities are much smaller. During the 1998-2008, we can easily find the prior infrastructural conditions have a decisive effect on the changes. The GuangShen traffic corridor which already had high network efficiency value showed lower changes, while the Eastern and Western PRD which had a relatively low network efficiency value in fist two stages has acquired enormous improvement in network efficiency. 
Figure 5: The change of land-based transport network efficiency (NE) in the PRD, 1988-1998 and 1998-2008
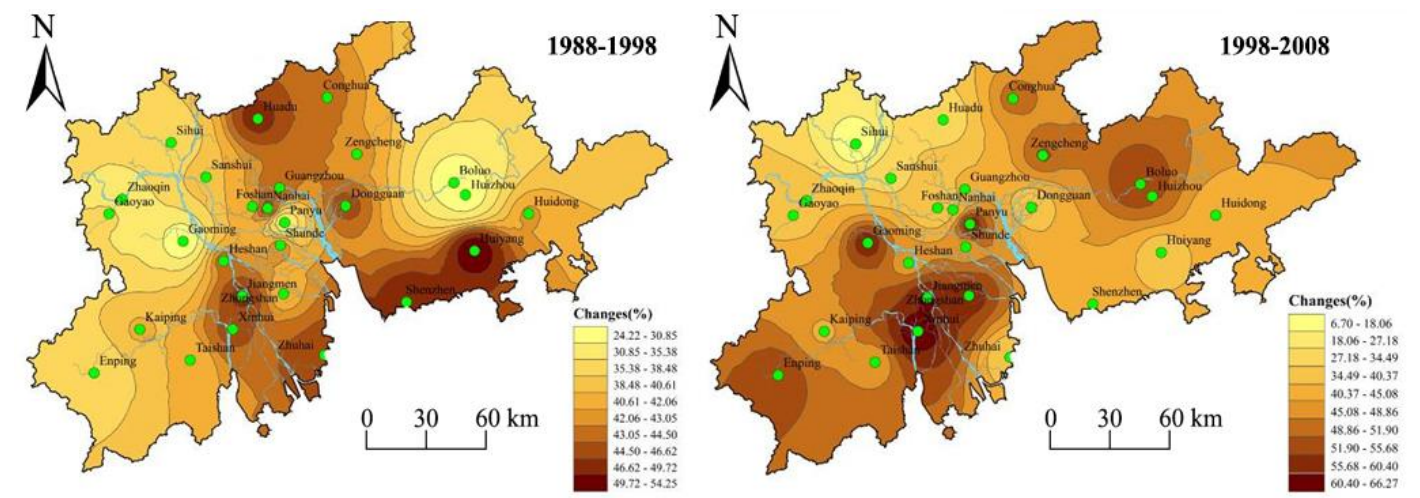

Table 3 summarizes the network efficiency in the PRD over time at the level of sub-regions. It can be observed from the table that the travelling efficiency within the transport network in the PRD is geographically uneven. From 1988 to 2008, the travelling efficiency between cities within Central PRD is higher than that of other regions. Among the three sub-regions, the Western PRD is the most disadvantaged. Travelling efficiency between cities in the Eastern PRD and those in the Western PRD are the poorest efficiency. Between 1988 and 1998, largely a result of the development of highway network completion, travelling efficiency between cities in these two sub-regions declined from 4.43 to 2.58, and further decreased to 1.32 in 2008.

In terms of spatial distribution, transport network development has relatively minor impacts on the pattern of network efficiency. From 1988 to 2008, the coefficient of variation (COV) of network efficiency value shows that the spatial disparity of network efficiency remained unchanged at 0.23 (table 2 ), which means the differences in the network efficiency between cities have become almost negligible.

\begin{tabular}{ccccc}
\multicolumn{2}{l}{ Table 3: Network efficiency in the PRD, 1988-2008 } & Central & Western & PRD \\
\hline E 1988 & & & & \\
Eastern & 3.81 & 4.52 & 4.43 & 5.16 \\
Central & & 2.84 & 3.56 & 4.17 \\
Western & & 3.93 & 6.3 \\
$b$ 1998 & & & 2.58 & 3 \\
Eastern & 2.21 & 2.65 & 2.46 & 2.94 \\
Central & & 2.4 & 2.75 & 4.3 \\
Western & & & 1.32 & 1.62 \\
$c$ 2008 & \multirow{2}{*}{1.31} & 1.39 & 1.35 & 1.53 \\
Eastern & & 1.23 & 1.64 & 2.46 \\
Central & & &
\end{tabular}

Notice: The detailed area of the Eastern PRD, Central PRD and Western PRD is mapped in Fig.1.

\subsection{Policy implications}

The major advantage of the network efficiency indicator adopted in this paper is that it can highlight the effects, of new infrastructures and determine the transport infrastructure needs of each city. Based on this, we can also gain further insights into the relationship between transport and urban development, and determine which policy should be carried out firstly. In this paper, we choose per capita GDP as a proxy for economic development. Based on the results, we construct the transportdevelopment matrix for 2008 in which the horizontal axis represents the network efficiency and the vertical axis per capita GDP, and where each city is located. Because the network efficiency value is in 
an inverse scale, which means the lower the value attained the more accessible is the place in relative terms, so we use the reciprocal of network efficiency value (1/network efficiency) as a proxy for transport infrastructural development level. Since the average reciprocal of network efficiency and per capita GDP scores for the 27 cities are 0.73 and 5.08 (million yuan), respectively, we can divide the matrix into four sub-matrices based on the average scores as shown in Fig.6. Those cities located in the second quadrant, for instance, ZH (Zhuhai) and FS (Foshan), represent relatively lower network efficiency, but higher per capita GDP. A policy implication for these cities is that they need to improve transport infrastructure first. On the other hand, those cities located in the fourth quadrant exhibit higher network efficiency but lower per capital GDP. By taking EP (Enping) as an example, its network efficiency is significantly higher than its per capita GDP. The policy implication is that it is necessary to improve their economic development by adopt other policy, rather than improving transport infrastructure. Of course, for those cities located in the third quadrant with both relatively lower network efficiency and per capita GDP, SH (Sihui) should, for example, consider both directions to improve the transport infrastructure and socio-economic development.

Figure 6: Network efficiency vs. per capital GDP

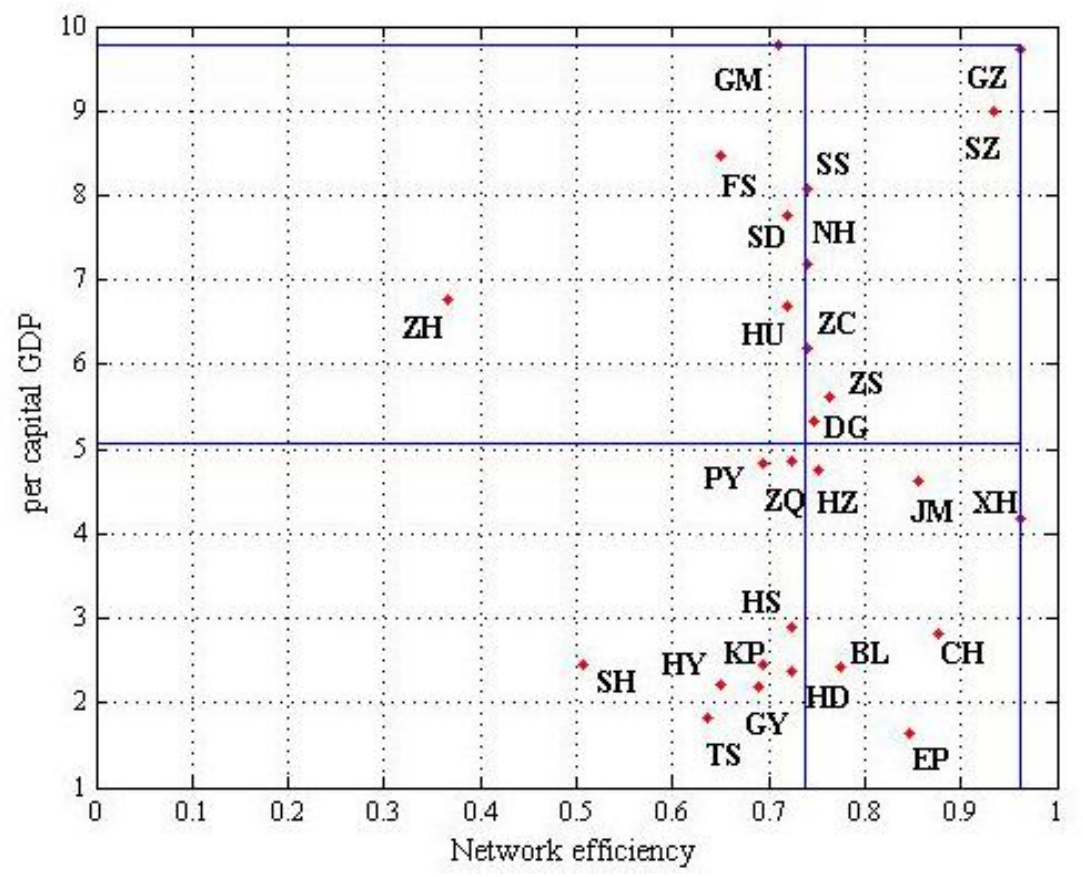

Notice: Per capital GDP data was obtained by compiled from the statistical yearbooks of individual municipalities, 2008.

\section{Limitations and future directions of research}

In this study, network efficiency approach adopted in this paper does not take into account the real transport demand between the cities within the PRD. This may be a strong assumption, given the different status of the cities and the polycentric network-hierarchy structure of the PRD, the real transport demand may have different weight on the network efficiency value. Therefore, in order to measure the network efficiency precisely, it seems sensible to further explore network efficiency considering the real transport demand. Furthermore, due to the unavailability of data, in this study we select travel time as the impedance term for network efficiency computation. Consequently, one possible avenue for future research could be to substitute the travel time with generalized cost of travel as the impedance term. Finally, in this paper we do not take into capacity constraint issues in the determination of road speeds. Thus, another potential issue for future research would be to evaluate the possibility of congestion effects on the actual road speeds. 


\section{Conclusion}

This paper applied network-based efficiency methods to analyse the network efficiency implication of the development of land-based transport network in the PRD. Compared with classical accessibility indicators, network-based efficiency measures are capable of measuring and singling out the effect of infrastructure improvements. The spatial pattern of network efficiency is different from the 'core-periphery' pattern derived from classical accessibility indexes. In 1988 and 1998, the network efficiency contour showed a 'corridor' pattern along the GuangShen traffic corridor between Guangzhou and Shenzhen in the eastern side of the Pearl estuary; but with the large-scale transport infrastructural construction and upgrading in many of the existing lines, the spatial pattern has changed from an original north-south corridor to east-west contiguous distribution pattern. From 1988 to 2008, the average network efficiency value decreases from 4.42 to 1.41 , a drop of 1.20 or $68.10 \%$. The differences in the network efficiency between cities are almost negligible during the research period.

Using network efficiency models allow us to closely inspect the relationship between transport and development. By comparing the network efficiency value and per capital GDP, we are able to identify highly coupling cities between transport and development as well as inefficient or low coupling cities that need be improved in transport infrastructure or economic development.

\section{Acknowledgements}

The authors would like to thank the reviewers of their constructive comments on an earlier version of this paper. This paper is developed from a project sponsored by the National Science Foundation of China (\#41501120).

\section{Citation information}

Gao, X., \& Li, T. (2018). Regional geographies of land transport networks in the Pearl River Delta mega-region, China: A longitudinal analysis. Journal of Sustainable Development of Transport and Logistics, 3(1), 37-52. doi:10.14254/jsdtl.2018.3-1.4

\section{References}

Bell, M. E., \& Feitelson, E. (1991). US economic restructuring and demand for transportation services. Transportation Quarterly, 45(4).

Botham, R. (1980). The regional development effects of road investment. Transportation Planning and Technology, 6(2), 97-108.

Charnes, A., Cooper, W. W., \& Rhodes, E. (1978). Measuring the efficiency of decision making units. European Journal of Operational Research, 2(6), 429-444.

China, N. B. o. S. o. (2012). Guangdong Statistical Yearbook. Beijing: China Statistics Press.

China, N. G. C. o. (2010). 1:4M-scale Topographic Database of the National Fundamental Geographic Information System of China (Publication no. http://nfgis.nsdi.gov.cn/nfgis/english/default.htm).

Farrell, M. J. (1957). The measurement of productive efficiency. Journal of the Royal Statistical Society. Series A (General), 120(3), 253-290.

Feng, C.-M., \& Wang, R.-T. (2000). Performance evaluation for airlines including the consideration of financial ratios. Journal of Air Transport Management, 6(3), 133-142. doi:http://dx.doi.org/10.1016/S09696997(00)00003-X

Fielding, G. J. (1992). Transit performance evaluation in the U.S.A. Transportation Research Part A: Policy and Practice, 26(6), 483-491. doi:http://dx.doi.org/10.1016/0965-8564(92)90029-7

Fielding, G. J., Babitsky, T. T., \& Brenner, M. E. (1985). Performance evaluation for bus transit. Transportation Research Part A: General, 19(1), 73-82.

Fielding, G. J., Glauthier, R. E., \& Lave, C. A. (1978). Performance indicators for transit management. Transportation, $7(4), 365-379$.

Garrison, W. L. (1960). Connectivity of the interstate highway system. Papers in Regional Science, 6(1), 121-137. 
Geertman, S. C., \& Van Eck, J. R. R. (1995). GIS and models of accessibility potential: an application in planning. International Journal of Geographical Information Systems, 9(1), 67-80.

Government, G. P. (2010). Planning of Integrated Infrastructure Development in the Pearl River Delta, 2009-2020.

Gutierrez, J., Gonzalez, R., \& Gomez, G. (1996). The European high-speed train network: predicted effects on accessibility patterns. Journal of Transport Geography, 4(4), 227-238.

Gutiérrez, J., Monzon, A., \& Piñero, J. (1998). Accessibility, network efficiency, and transport infrastructure planning. Environment and Planning A, 30, 1337-1350.

Gutiérrez, J., \& Urbano, P. (1996). Accessibility in the European Union: the impact of the trans-European road network. Journal of Transport Geography, 4(1), 15-25.

Hansen, W. G. (1959). How accessibility shapes land use. Journal of the American Institute of Planners, 25(2), 7376.

Harris, C. D. (1954). The, Market as a Factor in the Localization of Industry in the United States. Annals of the Association of American Geographers, 44(4), 315-348.

Hou, Q., \& Li, S.-M. (2011). Transport infrastructure development and changing spatial accessibility in the Greater Pearl River Delta, China, 1990-2020. Journal of Transport Geography, 19(6), 1350-1360.

House, C. R. P. (1988). The Time table of National Railway Operation. Beijing: China Railway Publishing House.

House, C. R. P. (1998). The Time table of National Railway Operation. Beijing: China Railway Publishing House.

House, C. R. P. (2008). The Time table of National Railway Operation. Beijing: China Railway Publishing House.

Karlaftis, M. G. (2004). A DEA approach for evaluating the efficiency and effectiveness of urban transit systems. European Journal of Operational Research, 152(2), 354-364.

Karlaftis, M. G., \& Tsamboulas, D. (2012). Efficiency measurement in public transport: Are findings specification sensitive? Transportation Research Part A: Policy and Practice, 46(2), 392-402. doi:http://dx.doi.org/10.1016/j.tra.2011.10.005

Keeble, D., Offord, J., \& Walker, S. (1988). Peripheral regions in a community of twelve member states: Office for official publications of the European communities Luxembourg.

Lao, Y., \& Liu, L. (2009). Performance evaluation of bus lines with data envelopment analysis and geographic information systems. Computers, Environment and Urban Systems, 33(4), 247-255. doi:http://dx.doi.org/10.1016/j.compenvurbsys.2009.01.005

Latora, V., \& Marchiori, M. (2001). Efficient behavior of small-world networks. Physical Review Letters, 87(19), 198701.

Latora, V., \& Marchiori, M. (2002). Is the Boston subway a small-world network? Physica A: Statistical Mechanics and its Applications, 314(1), 109-113.

Li, T., Cao, X., \& Huang, X. (2012). The relationship between spatial structure of accessibility and population change in Pearl River Delta. Geographical Research, 31(9), 1661-1672.

Lin, G. C. (2001). Metropolitan development in a transitional socialist economy: spatial restructuring in the Pearl River Delta, China. Urban Studies, 38(3), 383-406.

Linneker, B. J., \& Spence, N. A. (1992). Accessibility measures compared in an analysis of the impact of the M25 London Orbital Motorway on Britain. Environment and Planning A, 24(8), 1137-1154.

Liu, B.-L., Liu, W.-L., \& Cheng, C.-P. (2006). Efficiency analysis of container Terminals in china: an application of DEA approach. Unpublished manuscript, Nankai University/Soochow University, Taipei, Taiwan.

Loo, B. P. (1999). Development of a regional transport infrastructure: some lessons from the Zhujiang Delta, Guangdong, China. Journal of Transport Geography, 7(1), 43-63.

Martín, J. C., Gutierrez, J., \& Román, C. (2004). Data envelopment analysis (DEA) index to measure the accessibility impacts of new infrastructure investments: The case of the high-speed train corridor Madrid-BarcelonaFrench border. Regional Studies, 38(6), 697-712.

Mesbah, M., Currie, G., Lennon, C., \& Northcott, T. (2012). Spatial and temporal visualization of transit operations performance data at a network level. Journal of Transport Geography, 25, 15-26.

Morris, J. M., Dumble, P., \& Wigan, M. R. (1979). Accessibility indicators for transport planning. Transportation Research Part A: General, 13(2), 91-109. 
Nolan, J. F. (1996). Determinants of productive efficiency in urban transit. Logistics and Transportation Review, $32(3)$.

Oum, T. H., \& Yu, C. (1994). Economic efficiency of railways and implications for public policy: a comparative study of the OECD countries' railways. Journal of Transport Economics and Policy, 121-138.

Press, C. C. $(1988,1998,2008)$. Atlas of Chinese Highway Operating Mileage. Beijing: China Communication Press.

Talley, W. K., \& Anderson, P. P. (1981). Effectiveness and efficiency in transit performance: a theoretical perspective. Transportation Research Part A: General, 15(6), 431-436.

Tsamboulas, D. A. (2006). Assessing performance under regulatory evolution: A European transit system perspective. Journal of urban planning and development, 132(4), 226-234.

Vickerman, R. (1995). Location, accessibility and regional development: the appraisal of trans-European networks. Transport Policy, 2(4), 225-234.

Viton, P. A. (1997). Technical efficiency in multi-mode bus transit: A production frontier analysis. Transportation Research Part B: Methodological, 31(1), 23-39.

Viton, P. A. (1998). Changes in multi-mode bus transit efficiency, 1988-1992. Transportation, 25(1), 1-21.

Zhang, X., \& Kloosterman, R.C.. (2012). Connecting the "Workshop of the World":Intra- and Extra- Service Networks of the Pearl River Delta City-Region. Gawc Bulltein.

Xiaoshu, C., \& Xiaopei, Y. (2003). The impact of the evolution of land network on spatial structure of accessibility in the developed areas: The case of Dongguan city in Guangdong province. Geographical Research, 22(3), 305-312.

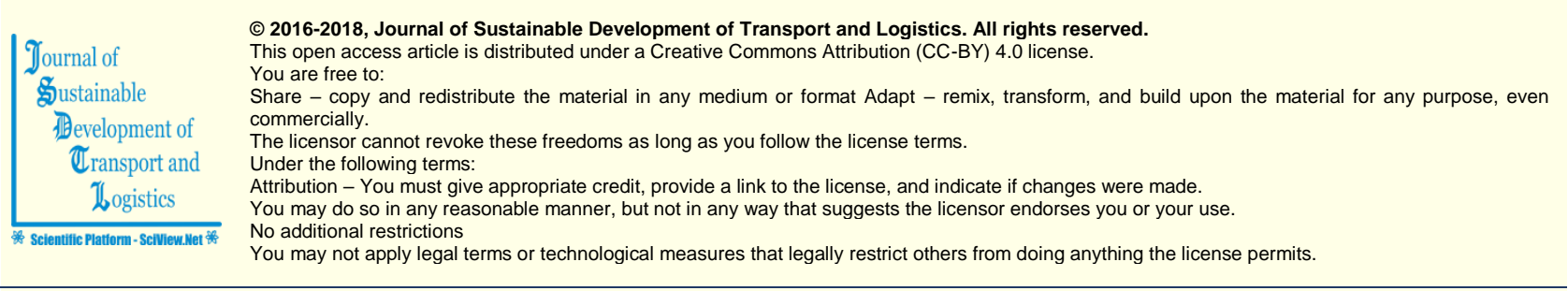

Journal of Sustainable Development of Transport and Logistics (ISSN: 2520-2979) is published by Scientific Publishing House "CSR",

Poland, EU and Scientific Publishing House "SciView", Poland, EU

Publishing with JSDTL ensures:

- Immediate, universal access to your article on publication

- High visibility and discoverability via the JSDTL website

- Rapid publication

- Guaranteed legacy preservation of your article

- Discounts and waivers for authors in developing regions

Submit your manuscript to a JSDTL at https://jsdtl.sciview.net/ or submit.jsdt|@sciview.net 